\title{
Allergieprävention durch Synbiotika?
}

\section{Eine frühe Modulation der Immunantwort über die Ernährung könnte vor der Entwicklung von Allergien wie die gegen Kuhmilch, schützen. An Mäusen wurde jetzt der Einfluss einer kombinierten Supplementation mit Pro- und Prebiotika auf die Sensibilisierung gegen Molke untersucht.}

— $s$ gibt eine Reihe von Oligosacchariden, _ die für den Menschen unverdaulich sind, aber immunmodulatorisch wirkenden Darmbakterien als Nährstoffe dienen. Die simultane Gabe solcher Oligosaccharide (Prebiotika) und Bakterien (Probiotika) ist möglicherweise ein allergiepräventiver Ansatz. Eine solche Kombination nennt man Synbiotikum.

Eine niederländische Studie untersuchte die Schutzwirkung von Probiotika, Prebiotika und Synbiotika im Hinblick auf eine Sensibilisierung gegen Molke an Mäusen. Dazu wurde den Tieren folgende Diät verabreicht: eine Prebiotika-Mixtur von kurzkettigen Galakto-Oligosaccha- riden und langkettigen Fructo-Oligosacchariden (Immunofortis) oder die probiotisch aktive Bakterienspezies Bifidobacterium breve (Stamm M-16V) oder eine synbiotische Mischung aus Pre- und Probiotikum. Zwei Wochen nach dem Beginn der Diät erfolgte die erste Sensibilisierung. Die allergische Reaktion auf eine intradermale Provokation am Ohr wurde anhand der Hautreaktion und eines Anaphylaxie-Scores gemessen, zusätzlich wurden Blutproben genommen.

Mäuse, die das Synbiotikum erhalten hatten, zeigten eine deutlich herabgesetzte Hautreaktion und geringere AnaphylaxieScores als Kontrollmäuse $(\mathrm{p}<0,01)$. Das
Pre- und das Probiotikum alleine verminderten die allergische Hautreaktion dagegen weitaus weniger und beeinflussten den Anaphylaxie-Score nicht. Die molkespezifischen $\mathrm{IgE}$ - und $\mathrm{IgG}_{1}$-Antworten veränderten sich in keiner Untersuchungsgruppe. Die Spiegel der $\operatorname{IgG}_{2 a}$-Antikörper waren jedoch in allen Interventionsgruppen höher als bei den Kontrollen ( $<<0,05)$.

Fazit: Die Gabe einer Kombination aus oligosaccharidhaltigem Prebiotikum und einem Bifidobakterienstamm als Probiotikum vermindert im Mausmodell allergische Reaktionen nach Sensibilisierung gegen Molke. Möglicherweise lässt sich mit einer solchen synbiotischen Mischung die Entwicklung einer Nahrungsmittelallergie auch beim Menschen verhindern.

bk

Schouten B et al. Cow milk allergy symptoms are reduced in mice fed dietary synbiotics during oral sensitization with whey. J Nutr 2009; 139: 1398-1403 